\title{
PENGARUH PENGGUNAAN MODEL KOOPERATIF TIPE TPS TERHADAP HASIL BELAJAR PKn KELAS V SEKOLAH DASAR
}

\author{
Oleh \\ Rezi Asmeli \\ Email: rezi.asmeli24@gmail.com \\ Email: reinita_reinita@yahoo.com
}

\begin{abstract}
Abstrak
Tujuan penelitian ini untuk membuktikan pengaruh penggunaan model Kooperatif tipe Think Pair Share terhadap hasil belajar siswa pada pembelajaran PKn di kelas V Sekolah Dasar Negeri 15 Padang Sarai. Jenis penelitian ini adalah Quasi Eksperimental Design. Teknik pengambilan sampel pada penelitian ini adalah Simple Random Sampling. Data diolah dengan uji perbedaan (t-test). Dari analisis uji-t di peroleh $\mathrm{t}_{\text {hitung }}=$ $3,08>\mathrm{t}_{\text {tabel }}=2,000$, pada signifikan $\alpha 0,05$. Hasil penelitian menunjukkan bahwa penggunaan model Kooperatif tipe Think Pair Share (TPS) berpengaruh tinggi terhadap hasil belajar siswa pada topik mendeskripsikan Wilayah Negara Kesatuan Republik Indonesia (NKRI) pada mata pelajaran PKn di kelas V SDN 15 Padang Sarai.
\end{abstract}

\section{Kata Kunci: Model Kooperatif Tipe Think Pair Share, Pembelajaran PKn}

\begin{abstract}
The purpose of this research was to prove the influenceof the use the Cooperatif model types Think Pair Share against results of student learning on the learning of PKn in class V 15 State Primary School Padang Sarai. This type of research was Quasi Experimental Design. The technigue of sampling in research this is a Simple Random Sampling. The data processed by a test of difference ( $t$-test). From the analysis of the test- $t$ in get $t_{\text {acount }}=3,08>t_{\text {table }}=2,000$, in significant $\alpha 0,05$. The result showed that the use of the Cooperative model types Think Pair Share (TPS) effect to the results of student learning on the topic describes the territory of the State Union of Republic of Indonesia (SO) on PKn Subjects in class V 15 State Primary School Padang Sarai.
\end{abstract}

Keywords: Coopeative Model Types Think Pair Share, Learning PKn 


\section{PENDAHULUAN}

Kooperatif Learning merupakan salah satu model pembelajaran yang dapat digunakan dalam proses pembelajaran. Model pembelajaran Kooperatif adalah bentuk pembelajaran dengan cara peserta didik belajar dan bekerja dalam kelompok secara kolaboratif dengan struktur kelompok yang bersifat heterogen (Rusman, 2011:202).

Pendidikan Kewarganegaraan (PKn) merupakan salah satu mata pelajaran yang harus dipelajari di Sekolah Dasar (SD) sampai keperguruan tinggi. Menurut Depdiknas (2006:271) "Mata pelajaran PKn merupakan mata pelajaran yang memfokuskan pada pembentukan warga negara yang memahami dan mampu melaksanakan hak dan kewajibannya untuk menjadi warga negara Indonesia yang cerdas, terampil, dan berkarakter sesuai dengan yang diamanatkan oleh Pancasila dan UUD 1945." Hal ini sejalan dengan pendapat Muhamad Erwin (2010:3) "Pendidikan Kewarganegaraan di Indonesia merupakan pendidikan kebangsaan dan kewarganegaraan yang berhadapan dengan keberadaan Negara Kesatuan Republik Indonesia, demokrasi, HAM, dan citacita untuk mewujudkan masyarakat madani Indonesia dengan menggunakan Filsafat Pancasila sebagai pisau analisisnya".

Pembelajaran PKn yang dipelajari di SD memiliki peranan yang sangat penting untuk menghasilkan peseta didik yang kreatif, berfikir kritis, tanggap dan inovatif. Menurut Depdiknas (2006:271) bahwa tujuan PKn adalah menjadikan peserta didik agar mampu:

1) Berpikir secara kritis, rasional, dan kreatif dalam menanggapi isu kewarganegaraan, 2) berpartisipasi aktif, bertanggung jawab, bertindak secara cerdas dalam kegiatan bermasyarakat, berbangsa, serta anti-korupsi, 3) berkembang secara positif, demokratis untuk membentuk diri berdasarkan karakter masyarakat Indonesia agar dapat hidup bersama dengan bangsa lain, 4) berinteraksi dengan bangsa lain dalam percaturan dunia secara langsung/ tidak langsung dengan memanfaatkan teknologi informasi dan komunikasi.

Proses pembelajaran yang sementara ini dilakukan di lembaga-lembaga pendidikan kita masih banyak yang mengandalkan cara-cara lama dalam penyampaian materinya. Orientasi pembelajaran biasanya masih berpusat pada guru atau teacher centered sehingga membuat siswa menjadi pasif dalam proses belajar mengajar. 
Sedangkan model pembelajaran yang dilakukan oleh guru harus membuat peserta didik aktif dalam pembelajaran, karena keaktifan peserta didik dapat mempengaruhi hasil belajar.

Pendidikan Kewaganegaraan (PKn) harus menggunakan model pembelajaran yang mampu meningkatkan partisipasi siswa agar mampu memadukan atau menyeimbangkan antara penguasaan materi dengan sikap dan perilakunya dalam kehidupan sehari-hari. Karena pendidikan harus mengembangkan anak didik agar mampu menolong dirinya sendiri, untuk itu anak didik perlu mendapatkan berbagai pengalaman dalam mengembangkan konsep-konsep, prinsip, generalisasi, intelek, inisiatif, kreativitas, kehendak dan emosi.

Dalam upaya meningkatkan kualitas pembelajaran PKn, guru menggunakan beberapa metode yang bervariasi, namun pemilihan berbagai metode pembelajaran yang banyak jenisnya tentu harus dipertimbangkan sesuai dengan karakteristik materi ajar yang menanamkan nilai kesadaran, tanggung jawab, persatuan dan bela negara. Dengan demikian perlu dikembangkan suatu model pembelajaran yang dapat membuat peserta didik aktif dan mampu bekerja sama dengan cara saling berbagi pengetahuan antar peserta didik dalam kelompok. Untuk mendapatkan kemampuan kerja sama peserta didik maka digunakan model pembelajaran kooperatif tipe Think Pair Share. Keunggulan dari model think pair share ini adalah dapat mengoptimalkan siswa dalam berpendapat, sebagaimana yang dikatakan menurut Alma, dkk (2010:95) "Model TPS dapat mengoptimalkan partisipasi siswa dalam mengeluarkan pendapat dan meningkatkan pengetahuan".

Berdasarkan hasil pretest yang dilakukan peneliti pada hari Senin, 17 Juli 2017 di kelas V SD Negeri 15 Padang Sarai terdapat hasil belajar peserta didik kelas V masih banyak yang tidak mencapai Kriteria Ketuntasan Minimal (KKM) atau belum mencapai ketuntasan belajar.Hal ini disebabkan karena siswa kurang aktif dan kurang memperhatikan pembelajaran yang dilakukan sehingga mempengaruhi hasil belajar peserta didik. Pemilihan model pembelajaran sangat penting dalam mencapai tujuan pembelajaran karena model pembelajaran mampu memotivasi peserta didik dan mengkondisikan peserta didik agar belajar secara aktif atas dasar kemampuan dan keyakinan sendiri serta dapat mengembangkan kreativitas peserta didik dalam menyelesaikan suatu permasalahan. 
Berdasarkan permasalahan di atas, peneliti tertarik untuk membuat rencana penulisan yang diberi judul "Pengaruh Penggunaan Model Pembelajaran Kooperatif Tipe Think Pair Share terhadap Hasil Belajar Siswa pada Pembelajaran PKn di Kelas V SDN 15 Padang Sarai".

Tujuan penelitian ini adalah "Membuktikan model pembelajaran kooperatif tipe think pair share berpengaruh tehadap hasil belajar pada materi wilayah Negara Kesatuan Republik Indonesia”.

\section{METODOLOGI}

Dalam penelitian ini, digunakan pendekatan kuantitatif dengan jenis penelitian eksperimen. Penelitian eksperimen yang dilakukan yaitu Quasi Eksperimental Design. Sugiyono (2013:114) menyatakan bahwa Quasi Experimental Design digunakan karena pada kenyataannya sulit mendapatkan kelompok kontrol yang digunakan untuk penelitian. Desain penelitian yang digunakan adalah Nonequivalent Control Group Design. Desain ini dibedakan dengan adanya pretest sebelum perlakuan diberikan. Penelitian ini dilaksanakan di Sekolah Dasar Negeri 15 Padang Sarai dan waktu penelitian dilaksanakan dari tanggal 17 Juli sampai dengan 2 Agustus 2017. Populasi dalam penelitian adalah seluruh siswa di kelas V Sekolah Dasar Negeri 15 Padang Sarai yang berjumlah 103 siswa. Teknik pengambilan sampel dengan cara Simple Random Sampling. Sampel penelitian ini berjumlah 68 orang yang terbagi ke dalam dua kelas.

Instrumen penelitian ini adalah tes hasil belajar untuk melihat aspek kognitif yang dilakukan diakhir penelitian. Tes di uji coba terlebih dahulu di Sekolah Dasar Negeri 18 Perumnas Air Tawar Selatan yang berbentuk soal pilihan ganda berjumlah 50 butir. Tes dilihat validasi, daya beda, indeks kesukaran dan reliabelitas soal, sehingga didapatkan tes hasil belajar PKn soal pilihan ganda berjumlah 36 butir yang diberikan kepada kedua kelas sampel yaitu Pretest dan Posttest.

Dalam penelitian ini terdapat dua variabel yaitu variabel bebas dan variabel terikat. Variabel bebas adalah variabel yang mempengaruhi atau yang menjadi sebab perubahan atau timbulnya variabel terikat. Variabel bebas pada penelitian ini adalah model kooperatif tipe think pair share. Sedangkan variabel terikat adalah variabel yang dipengaruhi atau yang menjadi akibat adanya variabel bebas.Variabel terikat pada 
penelitian ini adalah hasil belajar. Jenis data dalam penelitian ini adalah data primer dan data sekunder. Data primer adalah hasil belajar yang diperoleh dari hasil tes akhir setelah perlakuan diberikan. Sedangkan data sekunder adalah data yang diambil secara tidak langsung dari sumbernya.

Penelitian ini menggunakan dua kelas sampel yaitu kelas eksperimen dengan menggunakan model kooperatif tipe Think Pair Share dan kelas kontrol tidak menggunakan model kooperatif tipe Think Pair Share. Pengambilan sampel kelas eksperimen dan kelas kontrol berdasarkan pada nilai pretest. Setelah kedua sampel berdistribusi normal dan homogen peneliti menggunakan teknik pengambilan sampel dengan Simple Random Sampling yakni pengambilan sampel secara acak berdasarkan undian. Dari undian tersebut di dapat kelas VB sebagai kelas eksperimen dan kelas VA sebagai kelas kontrol.

Posttest diberikan pada kedua kelas sampel untuk melihat hasil belajar PKn siswa setelah dibeikan perlakuan, seberapa jauh pengaruh model kooperatif tipe Think Pair Share tehadap hasil belajar PKn siswa. Teknik analisis data menggunakan uji t $(t$ test) dengan taraf signifikansi $\alpha=0,05$. Rumus uji-t yang digunakan sebagai berikut:

$$
\begin{aligned}
\mathrm{t}_{0} & =\frac{Y_{1}-Y_{2}}{S_{1}} \text {, dimana } \\
\mathrm{S}_{\mathrm{e}} & =\sqrt{\frac{\left(n_{1}+n_{2}\right)\left(\Sigma y_{1}^{2}+\Sigma y_{2}^{2}\right)}{\left(n_{1}\right)\left(n_{2}\right)\left(n_{1+} n_{2}-2\right)}}=\sqrt{\frac{(d b+2)\left(\left(\Sigma y_{1}^{2}+\Sigma y_{2}^{2}\right)\right.}{\left(n_{1}\right)\left(n_{2}\right)(d b)}} \\
\Sigma \mathrm{y}_{1}{ }^{2} & =\Sigma \mathrm{Y}_{1}{ }^{2}-\frac{\left(\Sigma Y_{1}\right)^{2}}{n_{1}} \operatorname{dan} \Sigma \mathrm{y}_{2}{ }^{2}=\Sigma \mathrm{Y}_{2}{ }^{2}-\frac{\left(\Sigma Y_{2}\right)^{2}}{n_{2}}
\end{aligned}
$$

Jika $t_{0} \leq t_{\text {tabel }}$ maka hipotesis nihil $\left(\mathrm{H}_{0}\right)$ diterima

Jika $\mathrm{t}_{0}>\mathrm{t}_{\text {tabel }}$ maka hipotesis nihil $\left(\mathrm{H}_{0}\right)$ ditolak

$\mathrm{H}_{0} \quad$ : Tidak terdapat pengaruh model pembelajaran kooperatif tipe ThinkPair Share (TPS) yang signifikan terhadap hasil belajar peserta didik pada mata pelajaran PKn kelas V di SDN 15 Padang Sarai pada taraf signifikan $\alpha$ 0,05 .

$\mathrm{H}_{1} \quad$ : Terdapat pengaruh model pembelajaran kooperatif tipe Think Pair Share (TPS) yang signifikan terhadap hasil belajar peserta didik pada mata pelajaran PKn kelas V di SDN 15 Padang Sarai pada taraf signifikan $\alpha$ 0,05 . 


\section{HASIL PENELITIAN}

\section{Deskripsi Data}

a. Data pretest kedua kelas sampel

Pretest dilaksanakan dikelas VA dengan jumlah 34 siswa dan VB dengan jumlah 34 siswa.

Tabel 1. Data Hasil Pretest Kedua Kelas

\begin{tabular}{|c|c|c|}
\hline \multirow{2}{*}{ Variabel } & \multicolumn{2}{|c|}{ Pretest } \\
\cline { 2 - 3 } & Kelas Eksperimen (VB) & Kelas Kontrol (VA) \\
\hline $\mathrm{N}$ & 34 & 34 \\
\hline Nilai Tertinggi & 87 & 84 \\
\hline Nilai Terendah & 22 & 19 \\
\hline Mean & 55,70 & 48,05 \\
\hline SD & 17,55 & 16,33 \\
\hline SD $^{2}$ & 298,944 & 258,888 \\
\hline
\end{tabular}

Dari nilai kelas eksperimen diperoleh rata-rata nilai sebesar 55,70, standar deviasi 17,55 dan nilai varians 298,944. Sedangkan kelas kontrol dengan jumlah siswa 34 orang memperoleh nilai tertinggi 84 dan nilai terendah 19. Dari nilai kelas kontrol diperoleh rata-rata nilai sebesar 48,05, standar deviasi 16,33 dan nilai varians 258,888 . Untuk lebih jelasnya dapat dilihat pada grafik berikut:

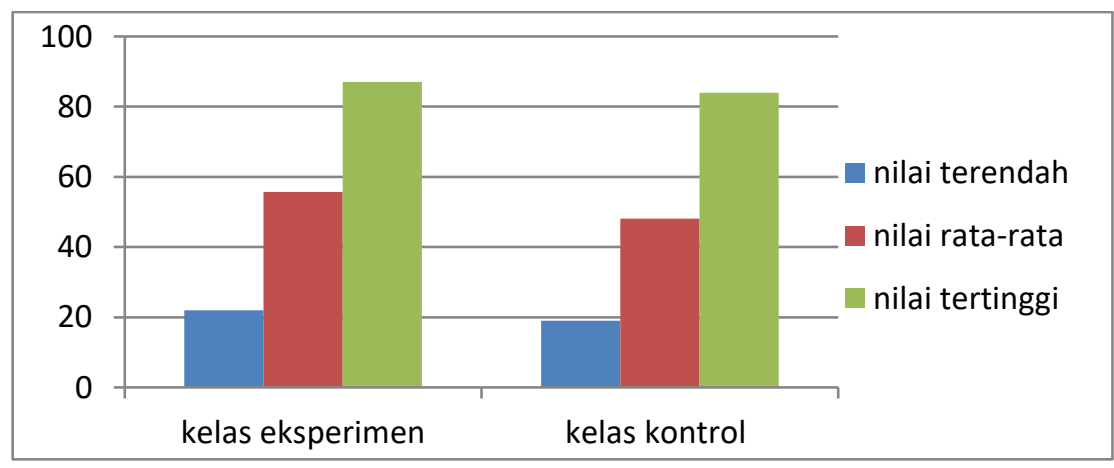

\section{Grafik 1. Perbandingan hasil pretest kelas eksperimen dan kelas kontrol}

b. Data posttest kedua kelas sampel

Posttest dilaksanakan dikelas VA dengan jumlah 34 siswa dan VB dengan jumlah 34 siswa.

Tabel 2. Data Hasil Postest Kedua Kelas 


\begin{tabular}{|c|c|c|}
\hline \multirow{2}{*}{ Variabel } & \multicolumn{2}{|c|}{ Postest } \\
\cline { 2 - 3 } & Kelas Eksperimen (VB) & Kelas Kontrol (VA) \\
\hline $\mathrm{N}$ & 34 & 34 \\
\hline Nilai Tertinggi & 97 & 92 \\
\hline Nilai Terendah & 58 & 39 \\
\hline Mean & 75,14 & 65,35 \\
\hline SD & 11,63 & 14,37 \\
\hline SD $^{2}$ & 131,102 & 200,505 \\
\hline
\end{tabular}

Dari nilai kelas eksperimen diperoleh rata-rata nilai sebesar 75,14, standar deviasi dan nilai varians 131,102. Sedangkan kelas kontrol dengan jumlah anak 34 orang memperoleh nilai tertinggi 92 dan nilai terendah 39. Dari nilai kelas eksperimen diperoleh rata-rata nilai sebesar 65,35, standar deviasi dan nilai varians 200,505. Untuk lebih jelasnya dapat dilihat pada grafik berikut:

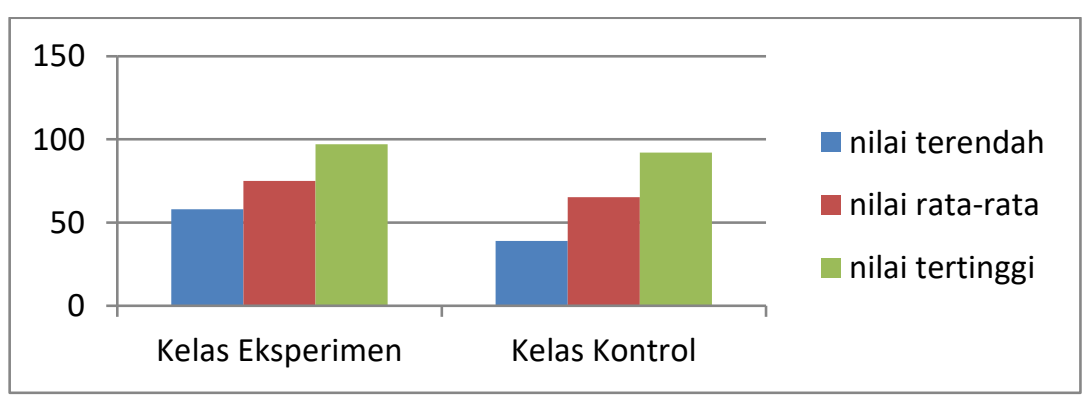

\section{Grafik 2. Perbandingan hasil postest kelas eksperimen dan kelas kontrol}

\section{Analisis Data}

Analisis data dilakukan untuk menarik kesimpulan tentang data hasil belajar.Untuk mengetahui apakah terdapat pengaruh yang signifikan untuk nilai kedua kelompok maka dilakukan uji hipotesis.Sebelum uji hipotesis dilakukan, terlebih dahulu dilakukan uji normalitas dan uji homogenitas setiap sampel.

1) Uji Normalitas

Data yang digunakan untuk uji normalitas ini adalah nilai tes akhir yang digunakan pada kelas eksperimen dan kelas kontrol diakhir pertemuan.Pada uji normalitas ini digunakan uji Kolmogorof-Smirnov seperti yang dikemukakan pada teknik analisis data. Berdasarkan uji normalitas kelas Eksperimen dan kelas Kontrol diperoleh Do dan Dt pada taraf nyata 0,05 untuk n >34 pada tabel 3 . 
Tabel 3. Hasil Perhitungan Pengujian Kolmogorof-Smirnov Kelompok Ekperimen dan Kelompok Kontrol

\begin{tabular}{|c|c|c|c|c|c|c|}
\hline No. & Kelas & $\mathbf{D}_{\mathbf{0}}$ & $\mathbf{D}_{\text {tabel }}$ & $\mathbf{n}$ & $\mathbf{A}$ & Keterangan \\
\hline 1. & Eksperimen & 0,1129 & 0,233 & 34 & 0,05 & Normal \\
\hline 2. & Kontrol & 0,0777 & 0,233 & 34 & 0,05 & Normal \\
\hline
\end{tabular}

2) Uji Homogenitas

Pengujian persyaratan yang kedua adalah pengujian hipotesis dengan menggunakan uji Bartlett.Pengujian ini bertujuan untuk mengetahui apakah data berasal dari kelompok yang homogen antara kelas Eksperimen dan Kontrol.Hasil perhitungan uji homogenitas dapat dilihat pada tabel 4.

Tabel 4. Hasil Uji Homogenitas Kelas Eksperimen dan Kelas Kontrol

\begin{tabular}{|c|c|c|c|c|}
\hline Kelas & $\boldsymbol{\alpha}$ & $\boldsymbol{X}_{\text {hitung }}$ & $\boldsymbol{X}_{\text {tabel }}$ & kesimpulan \\
\cline { 1 - 4 } Eksperimen & \multirow{2}{*}{0,05} & 1,450 & 3,841 & homogen \\
\cline { 1 - 3 } Kontrol & & & & \\
\hline
\end{tabular}

3) Uji Hipotesis

Setelah uji normalitas dan uji homogenitas dilakukan kemudian dilanjutkan dengan pengujian t-tes untuk mengetahui apakah terdapat pengaruh yang signifikan untuk nilai kedua kelompok.Apabila $t_{\text {hitung }}>t_{\text {tabel }}$ berarti terdapat pengaruh yang signifikan antara kedua kelompok.Berikut ini digambarkan pengolahan data dengan $t_{\text {test }}$ pada Tabel 5.

Tabel 5. Data Hasil Perhitungan Analisis Nilai Kelas Eksperimen dan Kelas Kontrol

\begin{tabular}{|c|c|c|}
\hline Aspek & Kelas Eksperimen & Kelas Kontrol \\
\hline $\mathrm{N}$ & 34 & 34 \\
\hline$\overline{\mathrm{X}}$ & 75,14 & 65,35 \\
\hline $\mathrm{SD}^{2}$ & 131,102 & 200,505 \\
\hline
\end{tabular}


Perhitungannya:

$$
\begin{aligned}
\overline{Y_{1}} & =\frac{2.555}{34}=75,14 \quad \overline{Y_{2}}=\frac{2.222}{34}=65,35 \\
\Sigma \mathrm{Y}_{1}{ }^{2} & =196.465-\frac{2.555^{2}}{34} \quad \Sigma \mathrm{Y}_{2}^{2}=152.034-\frac{2.222^{2}}{34} \\
& =4464,2647 \quad=6819,7647 \\
\mathrm{db} & =n 1+\mathrm{n} 2-2=34+34-2=66 \\
\mathrm{~S}_{\mathrm{e}}= & \sqrt{\frac{\left(n_{1}+n_{2}\right)\left(5 y_{2}^{1}+y_{2}^{2}\right)}{\left(n_{1}\right)\left(n_{2}\right)\left(n_{1}+n_{2}-2\right)}} \\
= & \sqrt{\frac{(34+34)(4464,2647+6819,7647)}{(34)(34)(34+34-2)}} \\
= & \sqrt{\frac{(68)(11284,19117)}{(34)(34)(66)}} \\
= & \sqrt{\frac{767.324,9996}{76.296}} \\
= & \sqrt{10,057} \\
= & 3,171 \\
\mathrm{~T}_{\text {hitung }} & =\frac{Y_{1}-\bar{Y}_{2}}{\mathrm{~S}_{e}} \\
& =\frac{75,14-65,35}{3,171} \\
& =\frac{9,79}{3,171} \\
& =3,08 \\
\text { tabel } & =2,000
\end{aligned}
$$

Untuk menguji hipotesis digunakan t-test. Dari hasil uji hipotesis dengan menggunakan t-test diperoleh hasil sebagai berikut:

Tabel 6. Hasil Pengujian dengan t-test

\begin{tabular}{|c|c|c|c|c|}
\hline No & Kelompok/Hasil & $\begin{array}{c}\text { Nilai rata- } \\
\text { rata Kelas }\end{array}$ & thitung & tabel $\boldsymbol{\alpha}$ 0,05 \\
\cline { 1 - 3 } 1. & Eksperimen & 75,14 & \multirow{2}{*}{3,08} & 2,000 \\
\hline 2. & Kontrol & 65,35 & & \\
\hline
\end{tabular}




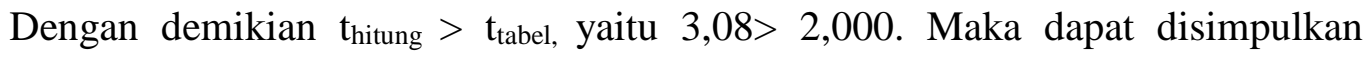
bahwa hasil belajar siswa yang mengikuti pembelajaran dengan Model Kooperatif tipe Think Pair Share lebih tinggi dari hasil belajar siswa yang mengikuti pembelajaran yang tidak menggunakan think pair share, dan terdapat pengaruh signifikan dari hasil belajar siswa antara kelas eksperimen yang menggunakan Model Kooperatif tipe Think Pair Share dibandingkan dengan kelas kontrol yang tidak menggunakan model pembelajaran Kooperatif tipe Think Pair Share.

\section{PEMBAHASAN}

Penelitian ini dilakukan pada 2 kelas yaitu kelas kontrol dan kelas eksperimen. Sebelum melakukan penelitian, peneliti memberikan pretest pada kelas eksperimen maupun kelas kontrol untuk mengetahui kemampuan awal kedua kelas.

Kelas kontrol tidak diberikan perlakuan atau proses pembelajaran tidak menggunakan model pembelajaran kooperatif tipe think pair share. Hasil nilai belajar PKn siswa yang tidak menggunakan model Kooperatif tipe think pair share lebih rendah dibandingkan dengan hasil nilai belajar PKn siswa di kelas eksperimen. Siswa yang dikelas kontrol cenderung pasif dalam belajar sehingga kurang memperhatikan guru pada saat pembelajaran, karena pembelajaran pada kelas kontrol ini hanya berpusat pada guru dan siswa terlalu sibuk dengan kegiatannya sendiri.

Pada kelas eksperimen diberi perlakuan dengan model Kooperatif tipe think pair share. Setelah pemberian perlakuan, diperoleh data berupa hasil nilai belajar PKn siswa yang menggunakan model Kooperatif tipe think pair share lebih tinggi dibandingkan dengan hasil nilai belajar PKn siswa yang tidak menggunakan model Kooperatif tipe think pair share. Karena siswa yang menggunakan model Kooperatif tipe think pair share lebih aktif dan tertarik sehingga siswa mampu menjawab pertanyaan yang diberikan oleh guru. Hal ini disebabkan dengan menggunakan model Kooperatif tipe think pair share siswa dituntut untuk berdiskusi dan berbagi dengan temannya sehingga melibatkan siswa untuk aktif dalam menemukan sebuah jawaban dari pertanyaan. Sesuai dengan pendapat Frag Lyman dan koleganya (dalam Hamdayana, 2014:201), menyatakan bahwa "Think pair share merupakan suatu cara efektif untuk membuat variasi suasana pola diskusi kelas". 
Menurut pendapat Trianto (2014:81) langkah-langkah model koopeatif tipe Think Pair Share yaitu: 1) Berpikir (Thinking) adalah guru mengajukan suatu pertanyaan atau masalah yang dikaitkan dengan materi pelajaran, dan meminta siswa menggunakan waktu beberapa menit untuk berpikir sendiri jawaban atau masalah, 2) Berpasangan (Pairing) adalah guru meminta siswa untuk berpasangan dan mendiskusikan apa yang telah mereka peroleh, interaksi selama waktu yang disediakan dapat menyatukan jawaban jika suatu pertanyaan yang diajukan, atau menyatukan gagasan apabila suatu masalah khusus yang diidentifikasi, 3) Berbagi (Sharing) adalah guru meminta setiap pasangan untuk berbagi dengan keseluruhan kelas yang telah mereka bicarakan.

Pembelajaran dengan model Kooperatif tipe think pair share pada kelas eksperimen dimulai dengan langkah pertama yaitu berpikir (think), pada tahap ini siswa diminta untuk berpikir tentang pertanyaan yang diajukan oleh guru yang berkaitan dengan materi pelajaran. Langkah kedua yaitu berpasangan (pair), pada tahap ini siswa diminta untuk berpasangan dan mendiskusikan hasil pemikirannya masing-masing untuk dipadukan menjadi sebuah jawaban yang utuh di LKS masing-masing. Dan langkah ketiga yaitu berbagi (share), pada tahap ini siswa bersama pasangan diminta untuk berbagi dengan seluruh warga kelas tentang apa yang telah mereka diskusikan didalam LKS tadi. Setelah siswa menyampaikan hasil LKS, guru menjelaskan materi sebagai penguatan dari apa yang sudah ditemukan siswa.

Setelah melakukan penelitian, peneliti memberikan posttest pada kelas eksperimen maupun kelas kontrol. Posttest ini dilakukan dengan tujuan untuk mengetahui ada tidaknya pengaruh yang signifikan dalam penggunaan model Kooperatif tipe think pair sharedari kedua kelas setelah diberi perlakukan yang berbeda. Hasil posttest menunjukkan nilai rata-rata kelas eksperimen ialah sebesar 75,14, sedangkan kelas kontrol memiliki nilai rata-rata sebesar 65,35. Terlihat nilai rata-rata kelas eksperimen yang menggunakan model Kooperatif tipe think pair share lebih tinggi dari nilai rata-rata kelas kontrol yang menggunakan ceramah. Siswa yang dikelas kontrol cenderung pasif dalam belajar sehingga kurang memperhatikan guru pada saat pembelajaran, karena pembelajaran pada kelas kontrol ini hanya berpusat pada guru dan siswa terlalu sibuk dengan kegiatannya sendiri. 
Model Kooperatif tipe think pair share ini dapat mengoptimalkan siswa dalam berpendapat, sebagaimana yang dikatakan menurut Alma, dkk (2010:95) "Model TPS dapat mengoptimalkan partisipasi siswa dalam mengeluarkan pendapat dan meningkatkan pengetahuan”. Dengan penggunaan model pembelajaran ini siswa dapat berpikir sendiri sesuai dengan kemampuannya, mempunyai tanggung jawab dalam menyelesaikan masalah yang ada serta mempunyai kebebasan dalam mengeluarkan pendapat, lalu guru meminta siswa berbagi kepada seluruh kelas tentang apa yang telah mereka diskusikan. Jika siswa sudah dapat menjelaskan dengan baik suatu materi pada siswa lain, maka dapat dikatakan siswa tersebut sudah dapat menguasai materi.

Pembelajaran dengan model Kooperatif tipe think pair share membuat siswa menjadi lebih mudah dalam memahami materi pembelajaran, mendorong siswa untuk aktif dalam mengikuti pembelajaran. Dari nilai posttest kedua kelompok yang diuji menggunakan uji t, bahwa $t_{\text {hitung }}$ sebesar 3,08 dan $t_{\text {tabel }}$ sebesar 2,000, dengan $t_{\text {hitung }}$ lebih besar dari $t_{\text {tabel }}(3,08>2,000)$, yang berarti terdapat perbedaan yang signifikan terhadap hasil belajar siswa yang menggunakan model pembelajaran kooperatif tipe think pair share dengan pembelajaran yang tidak menggunakan model kooperatif tipe think pair share. Analisis hipotesis dengan uji $t_{\text {hitung }}=3,08$ dan harga $t_{\text {tabel }}=2,000$ ini berarti $t_{\text {hitung }}$ tidak berada pada daerah penerimaan $\mathrm{H}_{\mathrm{o}}$ sehingga $\mathrm{H}_{\mathrm{o}}$ ditolak dan $\mathrm{H}_{1}$ diterima, artinya pembelajaran dengan menggunakan model kooperatif tipe think pair share berpengaruh terhadap hasil belajar kognitif siswa pada mata pelajaran PKn di kelas V SDN 15 Padang Sarai tahun ajaran 2017/2018.

Dengan demikian apa yang dikatakan dalam hipotesis pada penelitian ini dapat diterima bahwa terdapat pengaruh yang siginifikan terhadap hasil belajar siswa yang mengikuti pembelajaran dengan penggunaan model pembelajaran kooperatif tipe think pair share pada mata pelajaran PKn di kelas V SDN 15 Padang Sarai. Hal ini berarti terdapat pengaruh yang signifikan terhadap hasil belajar siswa kelas eksperimen yang menggunakan model pembelajaran kooperatif tipe think pair share dibandingkan dengan yang tidak menggunakan model pembelajaran kooperatif tipe think pair share.

Berdasarkan uraian diatas, dapat disimpulkan bahwa model pembelajaran kooperatif tipe think pair share berpengaruh terhadap hasil belajar PKn pada materi wilayah Negara Kesatuan Republik Indonesia di kelas V SDN 15 Padang Sarai. 


\section{SIMPULAN DAN SARAN}

Berdasarkan hasil penelitian dan pembahasan bahwa model pembelajaran Kooperatif tipe Think Pair Share berpengaruh signifikan terhadap hasil belajar PKn siswa kelas V SDN 15 Padang Sarai. Hal ini ditunjukkan oleh hasil uji hipotesis dengan menggunakan uji t, yaitu $\mathrm{t}$ hitung $(3,08)>\mathrm{t}$ tabel $(2,000)$ hasil belajar siswa yang menggunakan model Think Pair Share ini lebih tinggi dibandingkan dengan pembelajaran dengan metode ceramah.Hal ini disebabkan karena siswa yang menggunakan model Think Pair Share ini lebih aktif dalam belajar dibandingkan siswa yang tidak menggunakan model Think Pair Share.

Sehingga terdapat perbedaan yang signifikan antara hasil belajar kelas eksperimen yang belajar dengan model pembelajaran kooperatif tipe Think Pair Share (TPS) pada kelas VB dibanding kelas kontrol yang tidak menggunakan model pembelajaran kooperatif tipe Think Pair Share (TPS) pada kelas VA. Dapat disimpulkan penggunaan model pembelajaran kooperatif tipe Think Pair Share (TPS) berpengaruh terhadap hasil belajar siswa pada mata pelajaran PKn di kelas V SDN 15 Padang Sarai.

Mengacu pada kesimpulan yang telah dikemukakan di atas, maka peneliti menyarankan hal-hal berikut: (1) Diharapkan kepada guru mata pelajaran PKn di kelas V SDN 15 Padang Sarai untuk dapat menggunakan model pembelajaran kooperatif tipe Think Pair Share (TPS) sebagai variasi pembelajaran PKn yang relevan, sehingga siswa dapat termotivasi dan terlibat aktif dalam setiap kegiatan dalam proses pembelajaran. (2) Kepada guru-guru yang mengajar mata pelajaran PKn disarankan untuk menggunakan model pembelajaran kooperatif tipe Think Pair Share (TPS) dalam melakukan Proses Belajar Mengajar (PBM), tidak terbatas hanya dilakukan pada topik mendeskripsikan wilayah NKRI saja. Tetapi dapat juga digunakan pada topik lain yang relevan agar dapat meningkatkan kemampuan dan hasil belajar siswa pada mata pelajaran PKn. (3) Kepada Kepala Sekolah atau yang bertanggung jawab terhadap keberhasilan pembelajaran PKn agar dapat memotivasi guru dan membina guru-guru agar mau dan mampu melaksanakan model pembelajaran kooperatif tipe Think Pair Share (TPS) dengan tepat. 


\section{DAFTAR PUSTAKA}

Alma, dkk. 2010. Model Pembelajaran Inovatif. Medan: Media Persada.

Depdiknas. 2006. Kurikulum Tingkat Satuan Pendidikan. Jakarta: Depdiknas.

Erwin, Muhammad. 2010. Pendidikan Kewarganegaraan Republik Indonesia. Bandung: PT refika aditama.

Hamdayana, Jumata. 2014. Model dan metode Pembelajaran Kreatif dan Berkarakter. Jakarta: Ghalia Indonesia.

Rusman. 2011. Model-model Pembelajaran Mengembangkan Profesionalisme Guru. Jakarta: Raja Grafindo Persada.

Sugiyono. 2013. Metode Penulisan Pendidikan. Bandung: Alfabeta.

Trianto. 2014. Mendesain Model Pembelajaran Inovatif, Progresif dan Kontekstual. Jakarta: Kencana Prenada Media Group. 